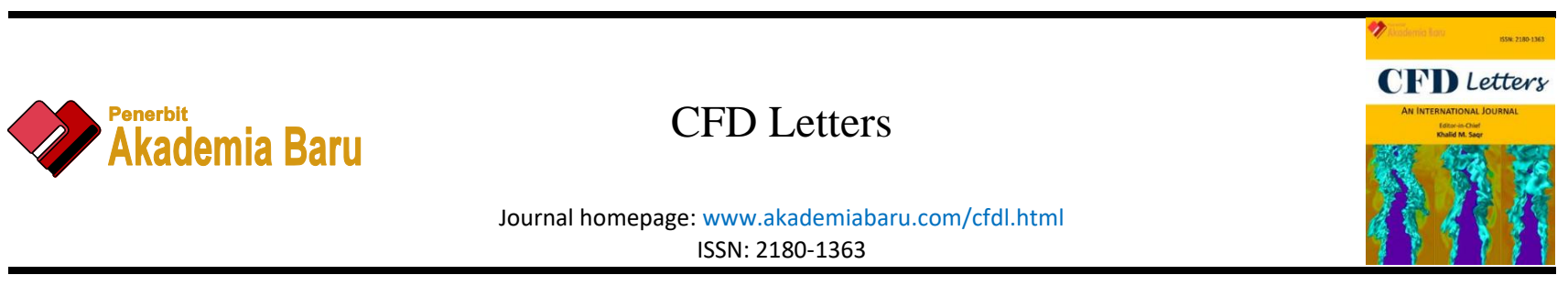

\title{
Biodiesel Composition Effects on Density and Viscosity of Diesel-Biodiesel Blend: A CFD Study
}

\author{
Mohammad Syahadan Maksom ${ }^{1, *}$, Nurul Fitriah Nasir², Norzelawati Asmuin², Muhammad \\ Faqhrurrazi Abd Rahman², Riyadhthusollehan Khairulfuaad ${ }^{2}$ \\ 1 Department of Mechanical Engineering, Politeknik Mukah Sarawak, 96400 Mukah, Sarawak, Malaysia \\ Centre for Energy and Industrial Environment Studies (CEIES), Universiti Tun Hussein Onn Malaysia, 86400 Batu Pahat, Johor, Malaysia
}

\section{ARTICLE INFO}

Article history:

Received 20 February 2020 Received in revised form 18 April 2020 Accepted 22 April 2020

Available online 30 April 2020

\section{Keywords:}

CFD simulation; blend process; diesel;

biodiesel; density; viscosity

\section{ABSTRACT}

\begin{abstract}
Biodiesel can be prepared by transesterification process, with methyl ester and glycerol as the final products. After the transesterification process, diesel and biodiesel are blended in mixing tank at certain temperature for a period of time until the mixture achieves the visual inspection, before it can be applied to $\mathrm{Cl}$ engine. However, there are lacks of information regarding the mixing effects on the density and viscosity of the biodiesel during the blending process. Therefore, this project is aimed to study the effects of different blending ratio on the density and viscosity of diesel biodiesel blend using Computational Fluid Dynamic (CFD) ANSYS Fluent software. It is also aimed to analyse the mixing pattern of blending process either both diesel and biodiesel are uniformly mix. By using CFD software, volume fraction, density and viscosity contours are generated and it is found that the density and viscosity has proportional relationship with biodiesel blends composition. The present study confirms previous findings and contributes additional evidence that suggests higher composition for higher density and viscosity.
\end{abstract}

Copyright $@ 2020$ PENERBIT AKADEMIA BARU - All rights reserved

\section{Introduction}

Carbon dioxide produced from diesel or gasoline fuel used by automobile is the primary factors on environmental damage. The product, tools and system which reduces environmental damage of human activities is define as Green Technology by KETTHA [1]. Nehrenheim [2] said, source of renewable energy such as solar energy, waves power and wind power can be convert directly to electricity and deliver to power grid without consuming earth resources. Serious efforts in green technology are to replace or reduce the fossil fuel usage. While fuels obtained from fossil sources were investigated by Knothe et al., [3] from the onset of these engines, biogenic materials also found some interest, primarily ethanol in the case of the spark-ignition engine and vegetable oils in the case of the compression ignition engine. The biodiesel can be prepared by transesterification process

\footnotetext{
* Corresponding author.

E-mail address: syahadan@pmu.edu.my (Mohammad Syahadan Bin Maksom)
} 
founded by Clifford [4]. Kusdiana and Saka [5] reported, through supercritical methanol state, the process can be complete within 2-4 min. Production of global biodiesel grew at $23 \%$ per annum as reported by Naylor et al., [6] between year 2005 and 2015. As shown in Figure 1, De Oliveira et al., [7] come out with world oil and gas production peak estimation graph. Between the late 60s and early 70s, United States oil and gas production would have its peak and tend to reduce.

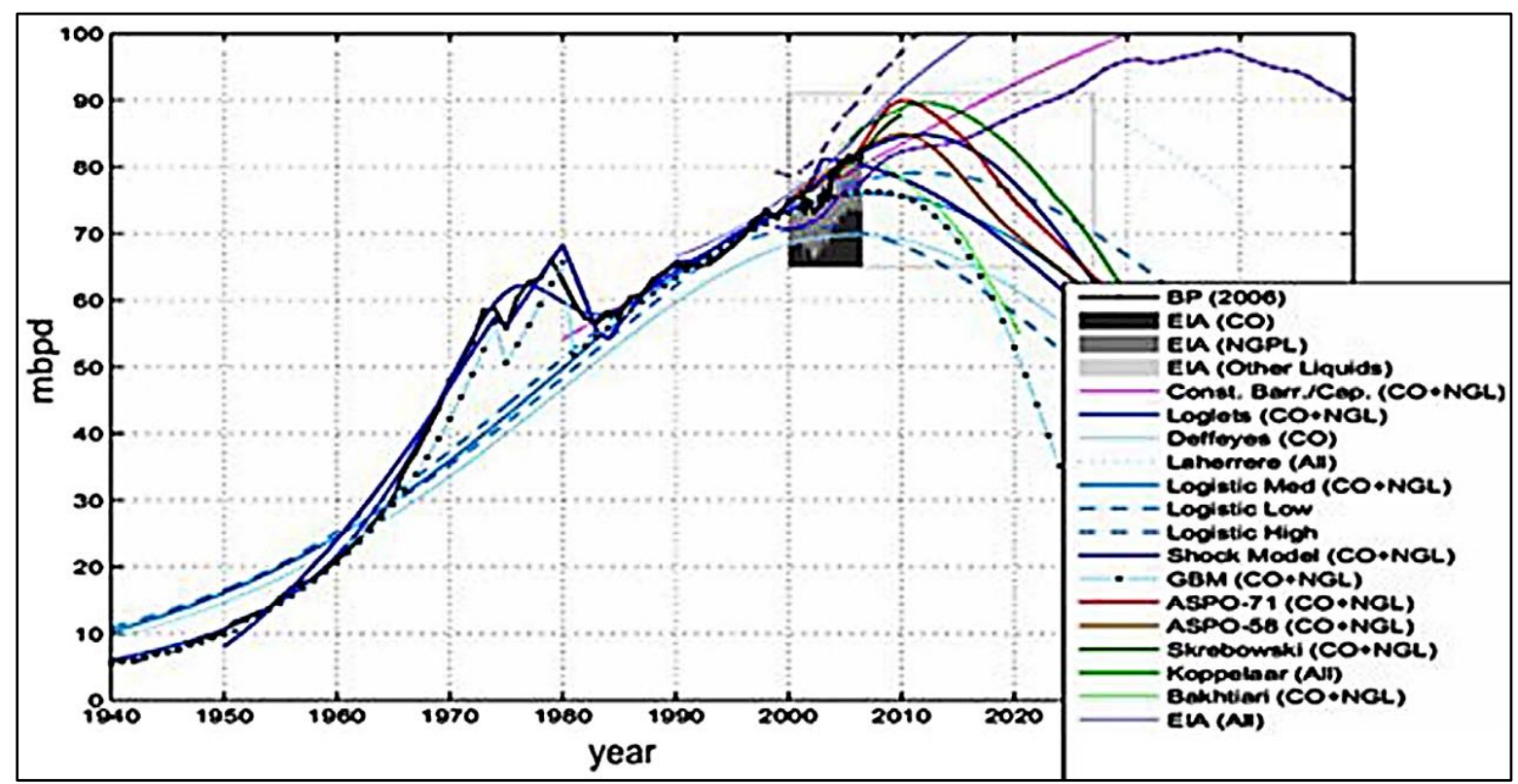

Fig. 1. World oil and gas production peak estimation

By 2030, International Energy Agency (IEA) has estimated 1.6\% increasing of global energy demand and approximately increasing of $65 \%$ because of countries development. Malaysia is one of the most rapidly developing countries among ASEAN countries next to Singapore as reported by Petinrin and Shaaban [8], with GDP of US\$15,400 per capita (PPP basis), and steady GDP growth of $4.6 \%$ in 2009.

In Malaysia, biodiesel program is conducted by the Malaysian Palm Oil Board (MPOB). Since June 2011 to January 2014, some of transportation and other subsidized sector were using B5 fuel (5\% biodiesel blended with 95\% fossil diesel). Starting November 2014, the involved sectors were using B7 fuel and in 2017, they began to use B10 fuel. Gunstone [9] reported the example of biodiesel raw material for other country are rapeseed in Canada, sun flower in Europe, soybean in USA, Brazil, Argentina and palm in Southeast Asia. The example of animal fat that can be used to produce biodiesel is fish fat and chicken fat given by Öner et al., [10].

Currently, fossil diesel is mix with biodiesel through blending process before it can be used in automobile and domestic application [11]. The biodiesel blends less than $20 \%$ is positively can use in most diesel equipment with no or minor modification in diesel engines as founded by Saxena et al., [12]. After the transesterification process, diesel and biodiesel are blended in mixing tank at certain temperature for a period of time until the mixture achieves the visual inspection, before it can be applied to $\mathrm{Cl}$ engine. However, there are lacks of information regarding the mixing effects on the density and viscosity of the biodiesel during the blending process. Therefore, this project studies the effects of different blending ratio on the density and viscosity using Computational Fluid Dynamic (CFD) ANSYS Fluent software. It is also aimed to analyses the mixing pattern of blending process either both diesel and biodiesel are uniformly mix. The purpose of this study is to investigate the effects of different composition of biodiesel on its density and viscosity by processing them at 60 RPM propeller rotational speed within 10 minutes processing time. 


\section{Methodology}

\subsection{Geometrical Modeling}

CAD drawing for mixing tank model used by Sharum [13] was constructed using SOLIDWORK 2014 software as shown in Figure 2, with dimension $L x d=500 \mathrm{~mm} \times 400 \mathrm{~mm}$. By using Ansys FLUENT 18.2 software, the blend process in mixing tank model is simulated at atmospheric pressure and ambient temperature.

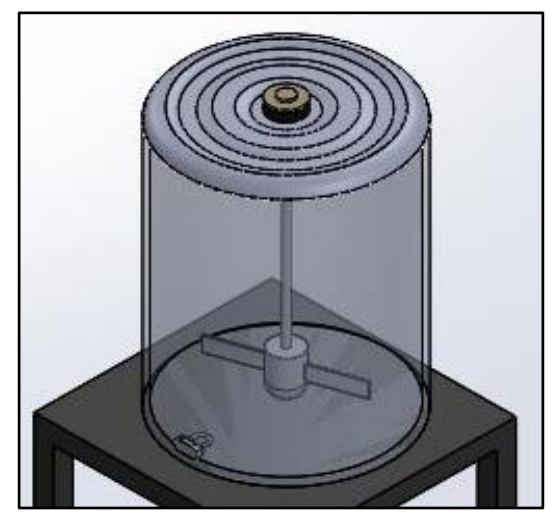

Fig. 2. SOLIDWORKS drawing

\subsection{Grid Independence Test}

In order to guarantee the solution was independent from the influence of grid size error, the geometry was coincided utilizing three diverse grid sizes as appeared in Figure 3 . The quantity of computational cells along the horizontal and vertical bearings is expanded while keeping up a square computational cell; a rundown of grid resolutions is exhibited in Table 1.

Fine grid captured some of the small-scale flow features which were unable to be detected in simulations with coarser computational cells. Medium setups are used to run this simulation since its result approach to fine meshing setup where percentage of error between fine and medium setup is $0.147 \%$. This can simplify the simulation calculation and reduce the calculation time.

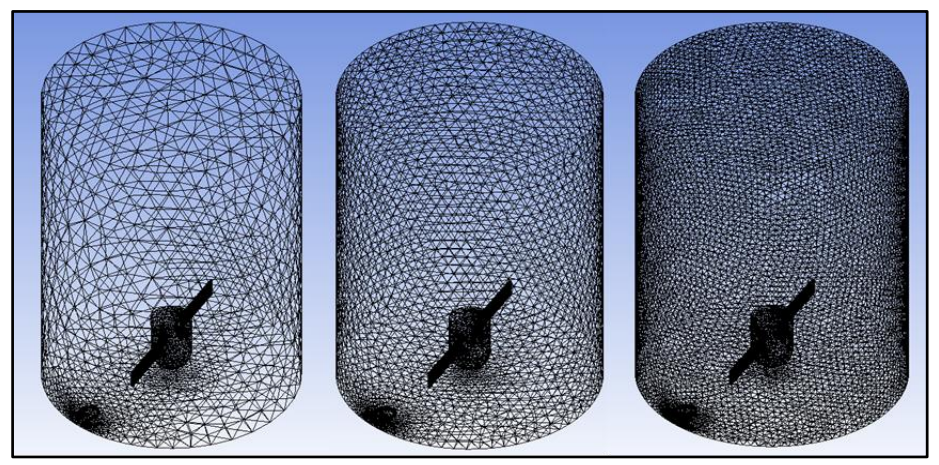

Fig. 3. right; Coarse, centre; Medium, left; Fine meshing

Table 1

Grid independent test for based model

\begin{tabular}{llll}
\hline Meshing & Skewness Mesh Metric & Number of Nodes & Number of Elements \\
\hline Coarse & 0.79232 & 63735 & 357492 \\
Medium & 0.82892 & 74574 & 414592 \\
Fine & 0.79923 & 111717 & 613610 \\
\hline
\end{tabular}




\subsection{CFD Simulation Method}

The solver must be setup based on the case study in order to run the analysis and calculation. Solver setup plays an important role in obtaining an accurate simulation results. Fluid zone is setup to operate as mesh motion and rotated along $\mathrm{Y}$-axis direction with rotational speed $60 \mathrm{rpm}$. For boundary condition, blade is setup as exhaust fan operate at 1 atm gauge pressure. While heater and cylinder wall is setup as stationary wall motion, no slips shear condition and standard roughness model. Fluid zone in mixing tank is marked to 2 regions that are biodiesel and diesel. Biodiesel volume was set at lower region of mixing tank and changed for biodiesel contain that is $5 \%, 10 \%, 15 \%, 20 \%$, $25 \%, 30 \%, 35 \%$ and $40 \%$. Then the calculation is setup as shown in Table 2.

Table 2

Simulation setup

\begin{tabular}{|c|c|c|c|}
\hline \multicolumn{4}{|l|}{ General setup } \\
\hline Type & Velocity Formulation & Time & Gravity \\
\hline Pressure-Based & Absolute & Transient & $\mathrm{Y}-9.81(\mathrm{~m} / \mathrm{s} 2)$ \\
\hline \multicolumn{4}{|l|}{ Model setup } \\
\hline Multhiphase & Phase & Energy & Viscous \\
\hline \multirow[t]{2}{*}{ Volume of Fluid } & Diesel-Primary phase & On & Realizable k-epsilon \\
\hline & \multicolumn{2}{|l|}{ Biodiesel- secondary phase } & Standard Wall Function \\
\hline \multicolumn{4}{|c|}{ Biodiesel properties in User Defined Databased by Mathur [14] } \\
\hline Material type & Density & Specific heat & Thermal conductivity \\
\hline Fluid & $878(\mathrm{~kg} / \mathrm{m} 3)$ & 2028.1 (j/kg.k) & $0.167(\mathrm{w} / \mathrm{m} . \mathrm{k})$ \\
\hline Viscosity & Molecular weight & Standard state enthalpy & Reference temperature \\
\hline 0.006 (kg/m.s) & $296.5(\mathrm{~kg} / \mathrm{kmol})$ & 0 (j/kgmol) & $25(c)$ \\
\hline \multicolumn{4}{|l|}{ Calculation setup } \\
\hline Time stepping method & Time step size & Number of time steps & Maximum iterations \\
\hline Fixed & $0.125 \mathrm{~s}$ & 4800 & 1 \\
\hline
\end{tabular}

\section{Results}

\subsection{Volume Fraction}

A mixture with similar chemical structure is expected not interact with each other; therefore the phase interaction can be neglected as suggested by Lim et al., [15]. Diesel biodiesel blends can be expected to act this way since both liquids are completely miscible, non-polar and their volumes are additive practically when blended. In this study the kinematic viscosity and volume fraction are utilized instead of the absolute viscosity and mole fraction, separately.

Figure 4 shows the contour of biodiesel volume friction in diesel biodiesel mixture after the blend process for 10 minutes with $60 \mathrm{rpm}$ blade rotational speed in mixing tank. Lower region are mark following the biodiesel composition and then patched for biodiesel volume, either diesel are patched for upper level.

As can be seen from the Figure 4, the biodiesel phase distribution for B15 to B40 reported significantly uniform distributed than the other two compositions. Highest biodiesel volume fraction can be seen at lower area of mixing tank. Poor design of mixing blade is one of the main causes the biodiesel phases cannot uniformly distribute to entire mixing tank. Overall, yellow contour are the main output of this blend process. This yellow phase will influence more on final properties of diesel biodiesel mixture. 

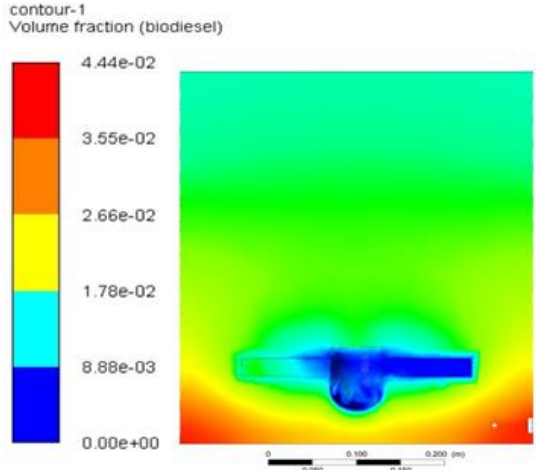

(a)
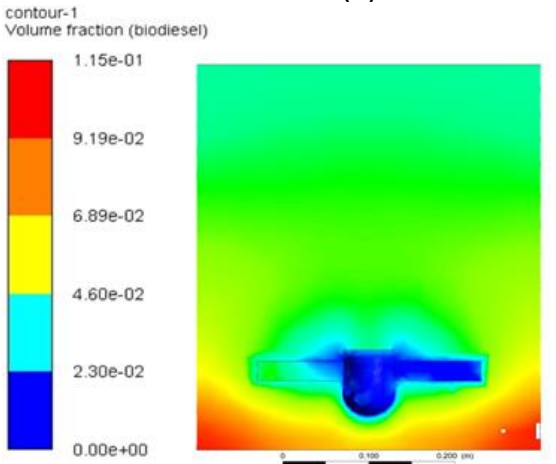

(c)

contour-1
Volume fraction (biodiesel)
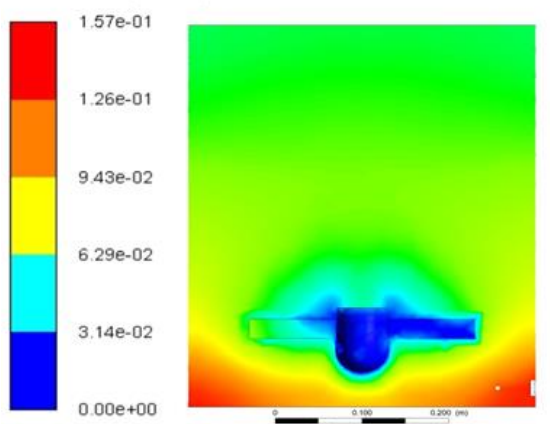

(e)

contour-1

Vontorion (biodiesel)
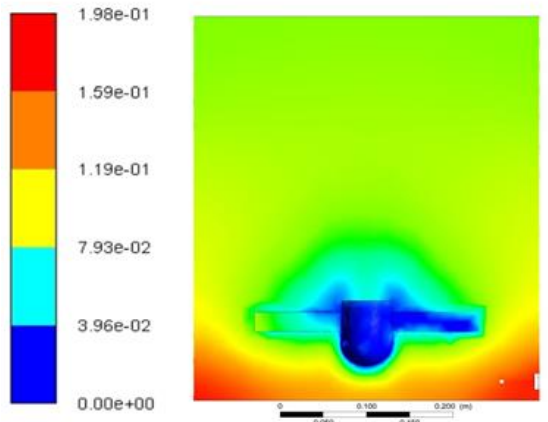

(g) contour-1
Volume fraction (biodiesel)
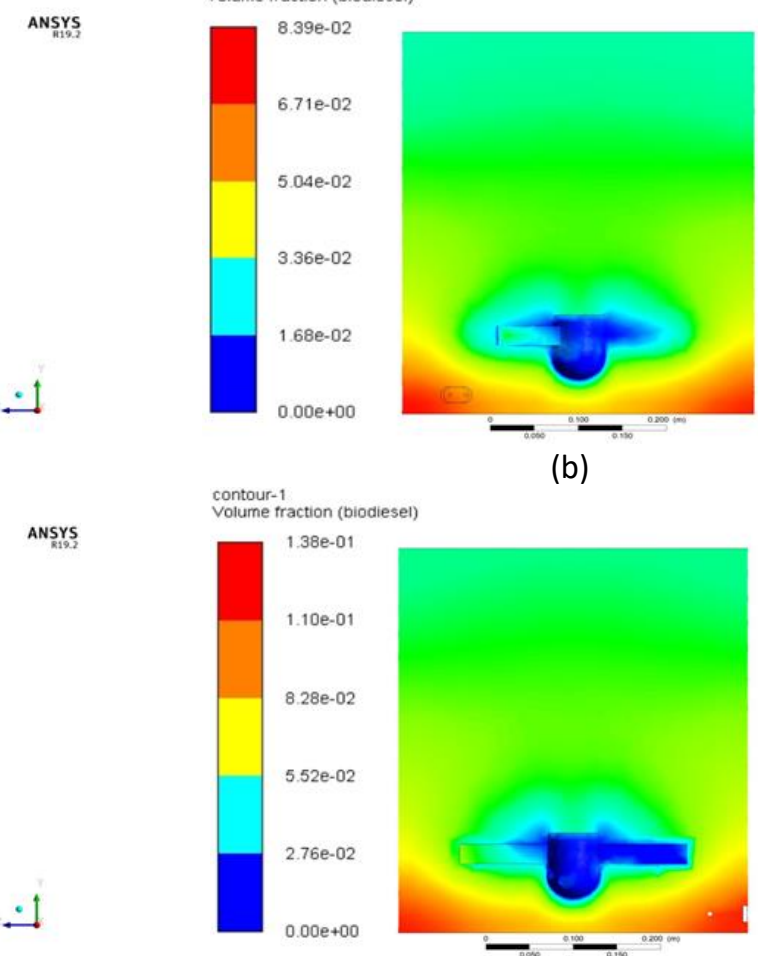
contour- 1
Volume fraction (biodiesel)
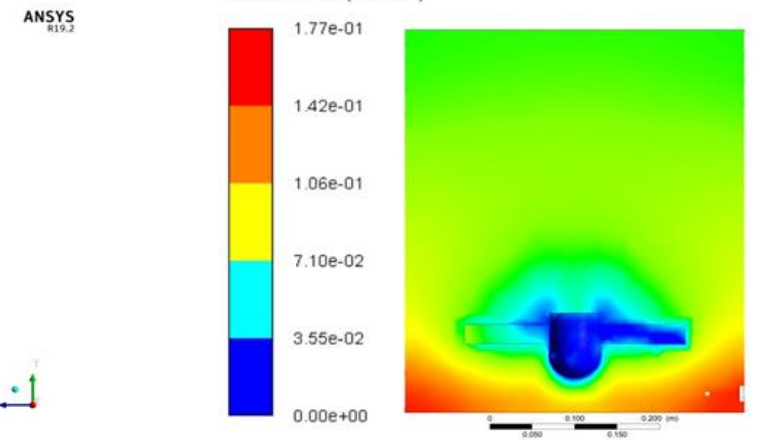

contour-1
Volume fraction (biodiesel)

ANSYS

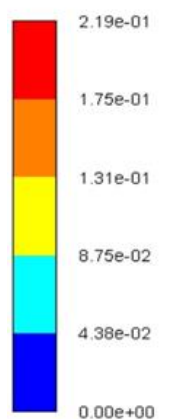

$0.00 \mathrm{e}+00$

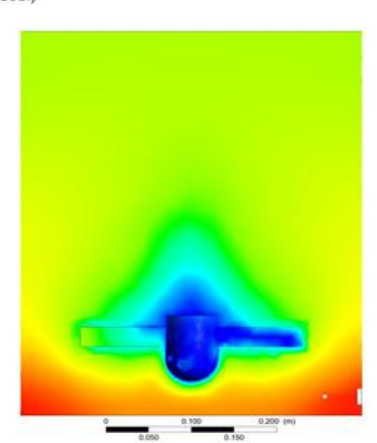

(h) (b)

(f)

ANSYS

ANSYS

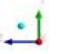

(d)

ANSYS

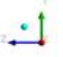

ANSYS

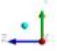

Fig. 4. Volume friction contour for diesel biodiesel blend. (a)B5, (b)B10, (c)B15, (d)B20, (e)B25, (f)B30, (g)B35 and (h)B40

\subsection{Density}

The variation in blend density with biodiesel content is shown in Figure 5. High densities of mixture are detected at bottom of mixing tank. 


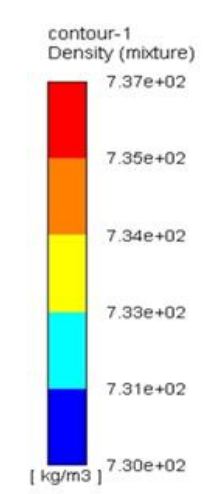

contour-1

Density (mixture)

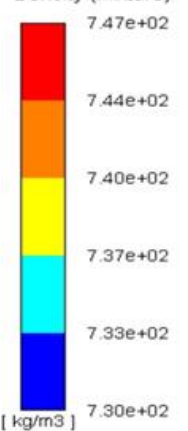

contour-1

Density (mixture)

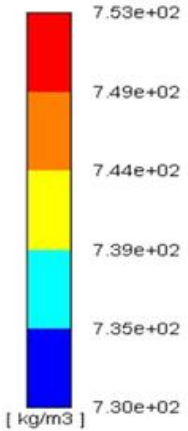

contour-1

Density (mixture)
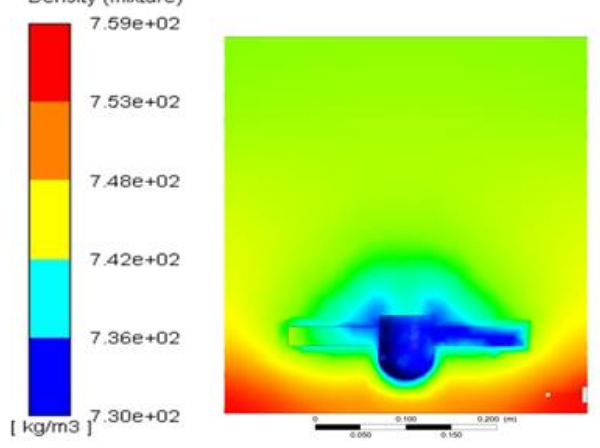

(g)

(a)

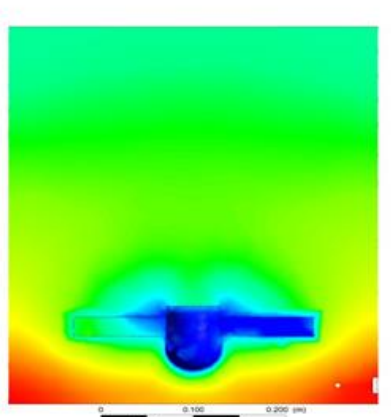

(c)

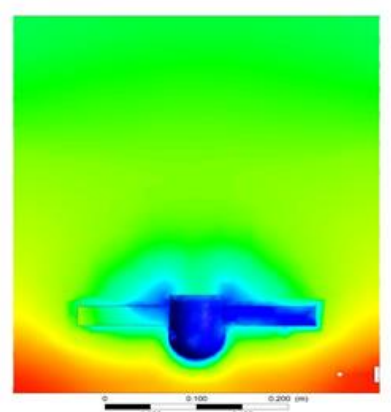

(e)
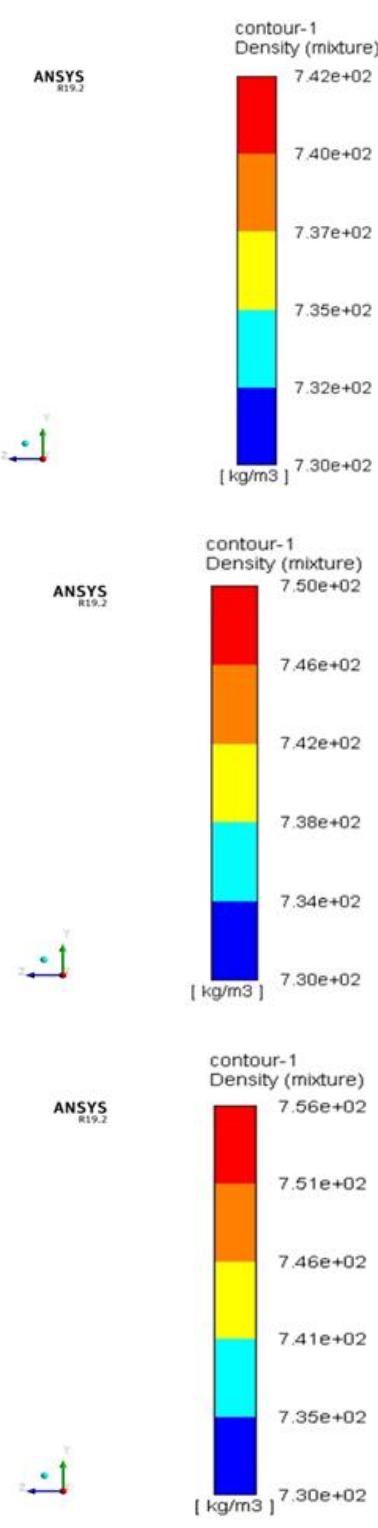

ANSYS

ANSYS

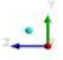

ANSYS

Fig. 5. Density contour for diesel biodiesel blend. (a)B5, (b)B10, (c)B15, (d)B20, (e)B25, (f)B30, (g)B35 and $(\mathrm{h}) \mathrm{B} 40$

This phenomenon is detected because of the high volume friction of biodiesel at this area. However, the lowest density of mixture is located at around the rotating blade represented with red colour region. High fluid flow around blade cause this area has lowest density as can be seen in Figure 5.

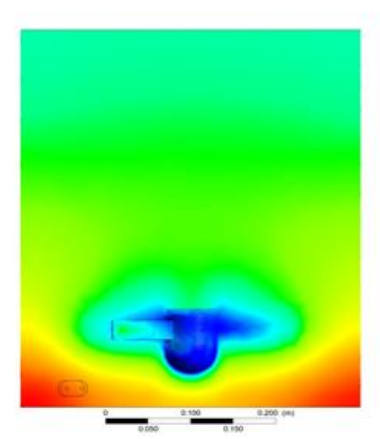

ANSYS

(b)

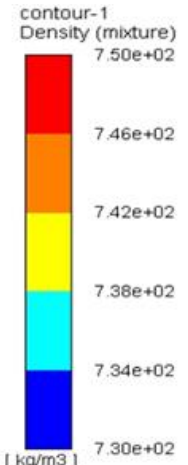

contour-1

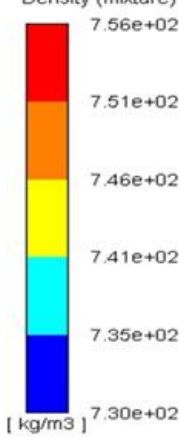

contour-1

Density (mixture)
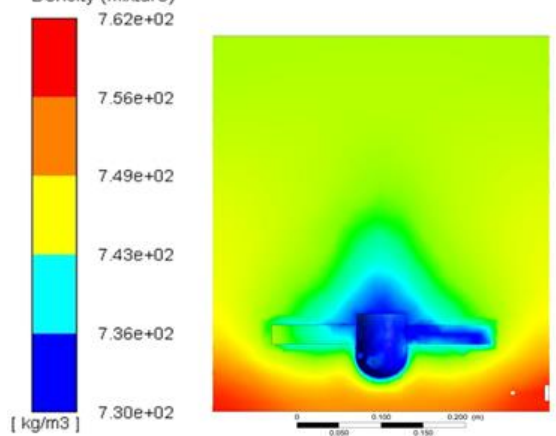

ANSYS

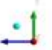

(h)

(f) 
Since biodiesel has high density compared to diesel, the biodiesel composition will influence the density of the mixture. Major density properties of this mixture are shown in yellow region. High density detected in $40 \%$ biodiesel blend Figure $5(\mathrm{~h})$ and lowest density detected in $5 \%$ biodiesel blend Figure 5(a).

Further analysis of the mixture density can be referred to the figure below. The results of the correlation analysis are presented in Figure 6. As was expected, density is directly proportional to biodiesel content. The density versus composition graph shows a uniform growth of density along biodiesel percentage in mixture. By using least square method as used by El-Araby et al., [16] to validate the result, the density of diesel biodiesel blend is plotted as in Figure 6 and regression coefficient, $R^{2}$ is 0.988 . The $R^{2}$ value shows prediction using least square method agreed with CFD simulation value.

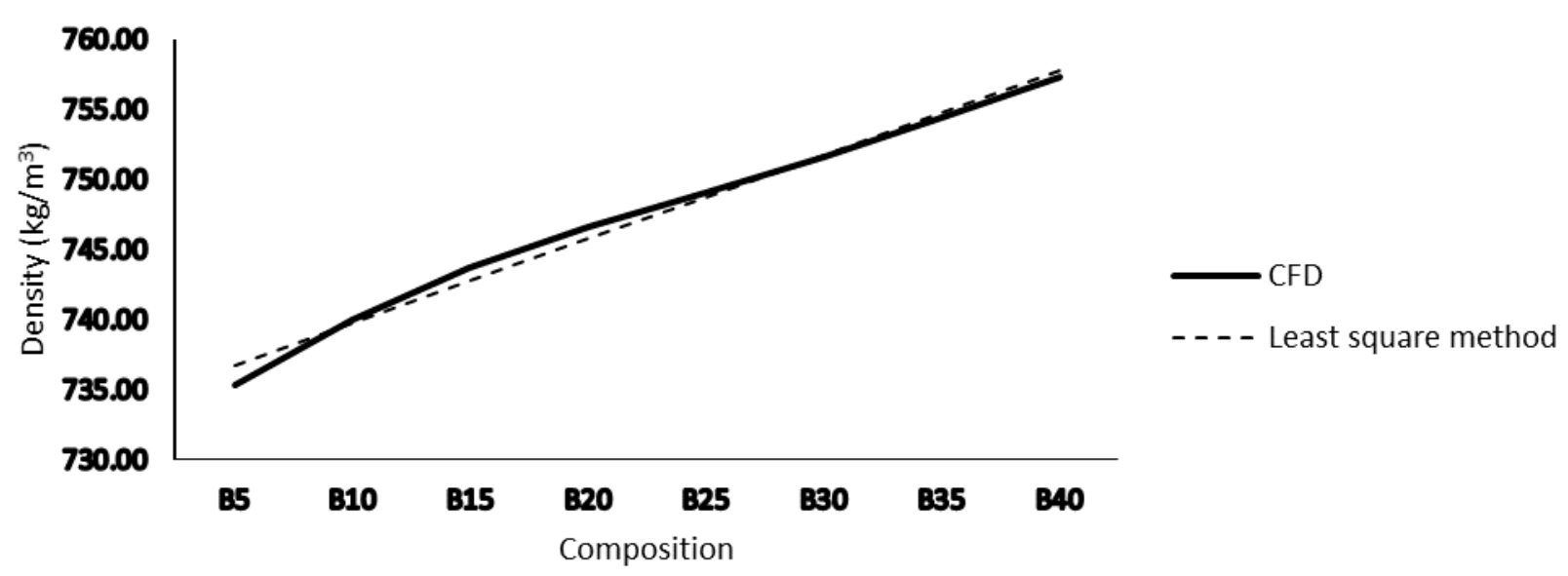

Fig. 6. Density versus composition graph

\subsection{Viscosity}

Figure 7 shows the effect of biodiesel content on the viscosity of the blends tested for eight representative compositions on diesel biodiesel blend. All contour recorded high viscosity located at the bottom of mixing tank. This high viscosity wad due to the high composition of biodiesel located at this area represented by red contour area.

Lowers viscosity can be seen located around blade area are represented by blue and cyan contour. This is because the high velocity of mixture was subjected to blade rotation. Except for B5 and B10, other blend process seems to have uniform mixer. As can be seen in Figure 8 , viscosity slightly increases with biodiesel content. There is a clear trend of viscosity increasing proportional to biodiesel composition.

Major phases formed in this blend process represented by yellow contour. This phase will have high properties influence on final mixture. However, there is no fully uniformly mix recorded in this blend process. It is due to poor blade design used in this study. More efficient blade design should be used for optimized the blend process. Verification of the result of this study is using least square method. The viscosity values using this method are plotted in viscosity versus composition graph as shown in Figure 8 and regression coefficient, $R^{2}$ of this line is 0.954 . This value shows the simulation results are acceptable and approach to actual value. 

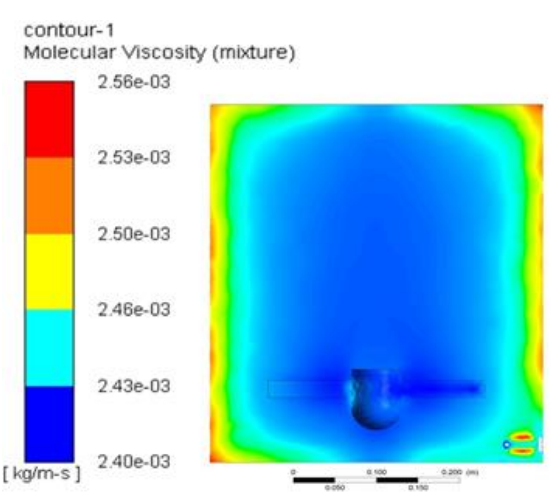

(a)

contour-1

Molecular Viscosity (mixture)
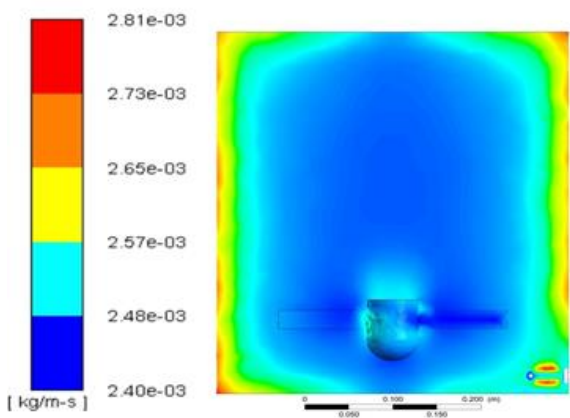

(c)

contour-1

Molecular Viscosity (mixture)
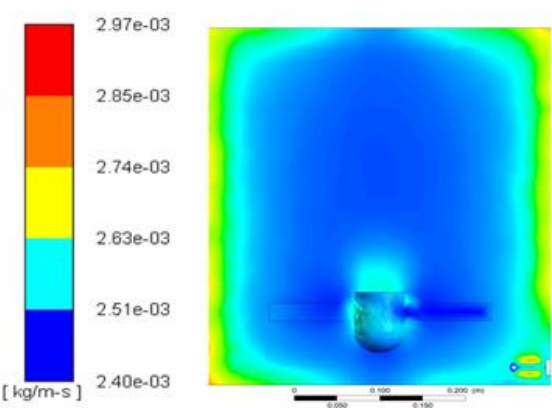

(e)

contour-1

Molecular Viscosity (mixture)
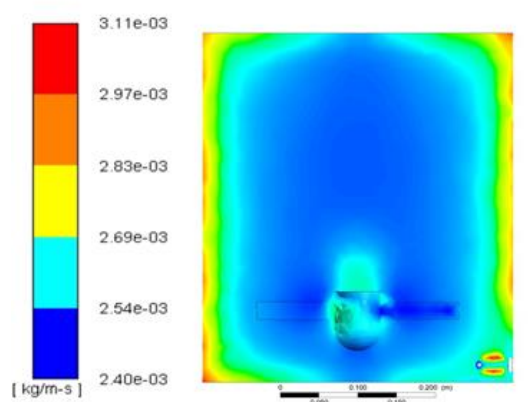

(g) contour-1

Molecular Viscosity (mixture)
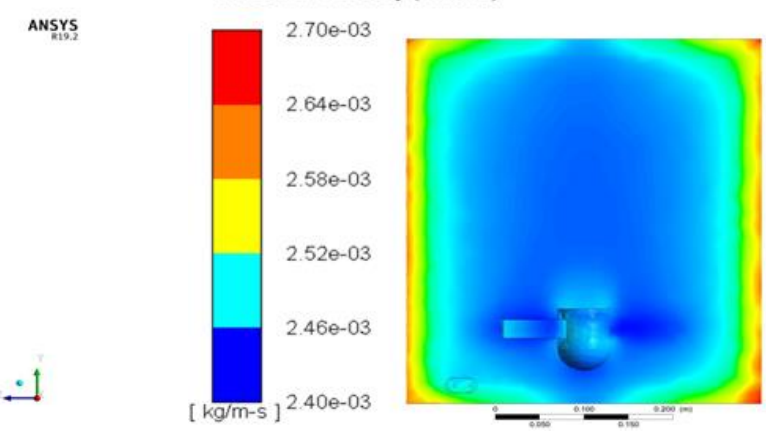

ANSYS

(b)

contour-

Molecular Viscosity (mixture)
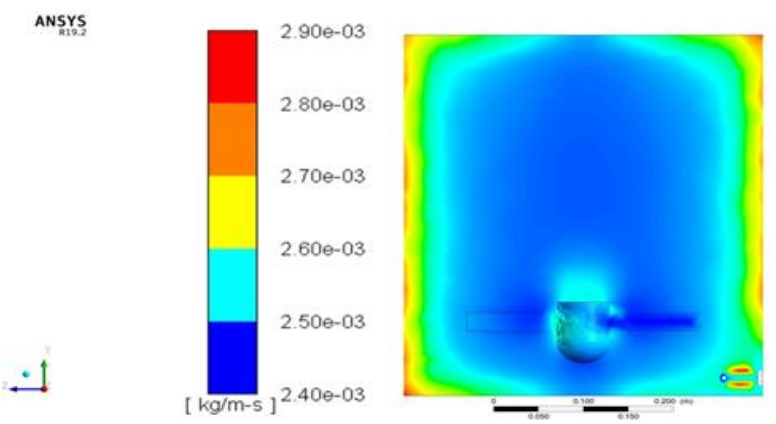

ANSYS

(d)

contour-1

Molecular Viscosity (mixture)
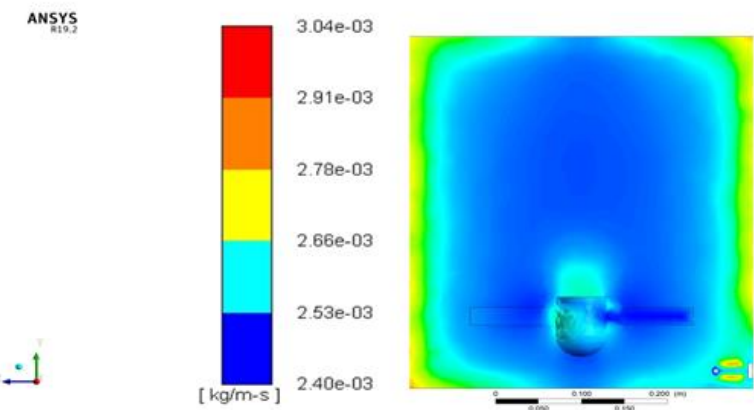

ANSYS

contour-1 Molecular Viscosity (mixture)
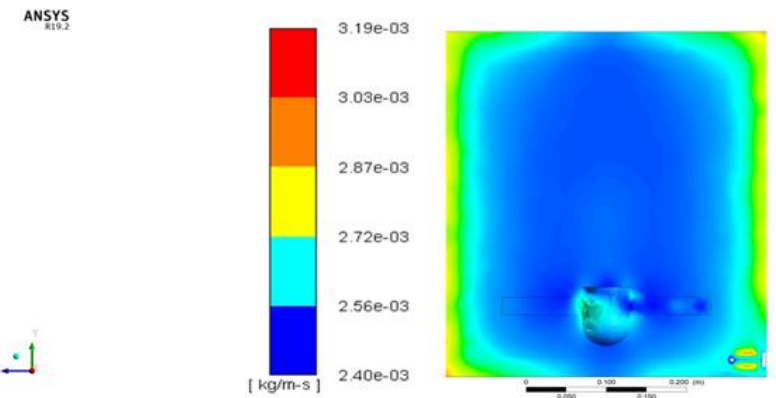

ANSYS

(h)

Fig. 7. Viscosity contour for diesel biodiesel blend. (a)B5, (b)B10, (c)B15, (d)B20, (e)B25, (f)B30, (g)B35 and (h)B40 


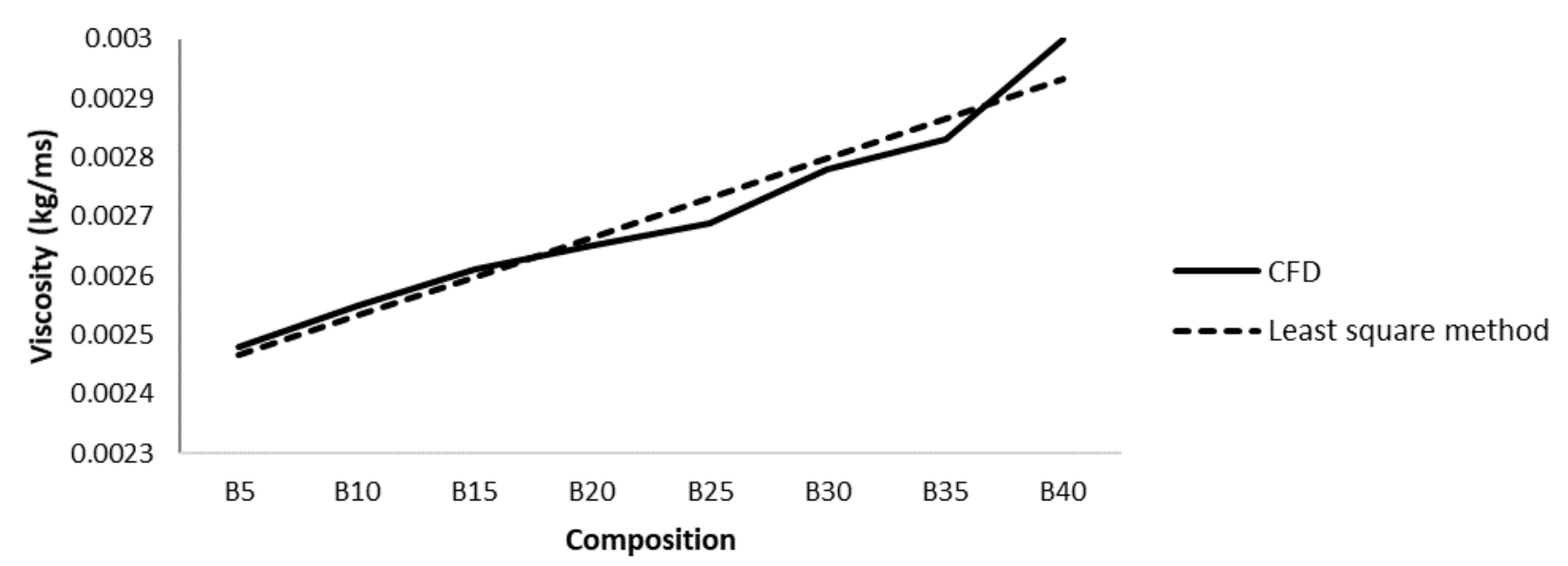

Fig. 8. Viscosity of biodiesel blends

\section{Conclusions}

This study set out to determine the relationship between density and viscosity with biodiesel composition during blend process. Returning to the hypothesis posed at the beginning of this study, it is now possible to state that biodiesel composition has influence on density and viscosity for biodiesel blends. One of the more significant findings to emerge from this study is that biodiesel density and viscosity are most influence factors for diesel biodiesel mixture properties.

However, the findings in this study were subjected to at least three limitations. First, only one blade design was used in this simulation. The volume friction contour shows this blade design cannot mix the diesel biodiesel phases uniformly. The evidence from this study suggests that some modification on blade can be made for proper blend process. Second limitation is the time factors were not investigated in this study. Thirdly, the study did not evaluate the temperature influence during blend process.

This research extends our knowledge on how diesel and biodiesel phases mix during blend process in mixing tank. The findings from this study make several contributions to the current literature. First, suitable blade design can help diesel biodiesel mix uniformly. Secondly, a suitable setup used will optimize this simulation process. This research will serve as a base for future studies on diesel biodiesel blend process optimization especially on blade design. The study also confirmed the findings from Benjumea et al., [17] which found that density and viscosity slightly increases with biodiesel content. This research extends our knowledge of biodiesel phases mixing.

\section{Acknowledgment}

The authors acknowledge the financial support from the Universiti Tun Hussein Onn Malaysia, Batu Pahat, Johor, Malaysia.

\section{References}

[1] Green Purchasing Network Malaysia. "Definition of Green Technology by KETTHA" 2010.

[2] Nehrenheim, Emma. "Introduction to renewable energy." (2013).

[3] Knothe, Gerhard, and Luis F. Razon. "Biodiesel fuels." Progress in Energy and Combustion Science 58 (2017): $36-59$. https://doi.org/10.1016/j.pecs.2016.08.001

[4] Clifford, C. "The Reaction of Biodiesel: Trans-eterification." The Pennsy/vania State University 7 (2017).

[5] Kusdiana, Dadan, and Shiro Saka. "Kinetics of transesterification in rapeseed oil to biodiesel fuel as treated in supercritical methanol." Fuel 80, no. 5 (2001): 693-698.

https://doi.org/10.1016/S0016-2361(00)00140-X

[6] Naylor, Rosamond L., and Matthew M. Higgins. "The political economy of biodiesel in an era of low oil prices." Renewable and Sustainable Energy Reviews 77 (2017): 695-705. 
https://doi.org/10.1016/j.rser.2017.04.026

[7] De Oliveira, Fernando C., and Suani T. Coelho. "History, evolution, and environmental impact of biodiesel in Brazil: A review." Renewable and Sustainable Energy Reviews 75 (2017): 168-179.

https://doi.org/10.1016/i.rser.2016.10.060

[8] Petinrin, J. O., and Mohamed Shaaban. "Renewable energy for continuous energy sustainability in Malaysia." Renewable and Sustainable Energy Reviews 50 (2015): 967-981.

https://doi.org/10.1016/i.rser.2015.04.146

[9] Gunstone, Frank D. "Supplies of vegetable oils for non-food purposes." European journal of lipid science and technology 113, no. 1 (2011): 3-7. https://doi.org/10.1002/ejlt.201000104

[10] Öner, Cengiz, and Şehmus Altun. "Biodiesel production from inedible animal tallow and an experimental investigation of its use as alternative fuel in a direct injection diesel engine." Applied energy 86, no. 10 (2009): 21142120. https://doi.org/10.1016/i.apenergy.2009.01.005

[11] Norhidayah Mat Taib, Mohd Radzi Abu Mansor, Wan Mohd Faizal Wan Mahmood, and Nik Rosli Abdullah. "Simulation Study of Combustion Characteristics of Diesel-Ethanol-Palm Oil Methyl Ester Blends in Diesel Engine." Journal of Advanced Research in Fluid Mechanics and Thermal Sciences 44, no. 1 (2018): 149-156.

[12] Saxena, Parag, Sayali Jawale, and Milind H. Joshipura. "A review on prediction of properties of biodiesel and blends of biodiesel." Procedia Engineering 51 (2013): 395-402. https://doi.org/10.1016/i.proeng.2013.01.055

[13] M. S. A. Sharum. "Design and Fabrication a Mixer for Compactibility Study on Biodiesel." 2018.

[14] Mathur, Yash Bansi. "Economics, combustion and performance assessment of a biodiesel engine." (2013).

[15] Lim, Steven, and Lee Keat Teong. "Recent trends, opportunities and challenges of biodiesel in Malaysia: an overview." Renewable and Sustainable Energy Reviews 14, no. 3 (2010): 938-954.

https://doi.org/10.1016/i.rser.2009.10.027

[16] El-Araby, R., Ashraf Amin, A. K. El Morsi, N. N. El-Ibiari, and G. I. El-Diwani. "Study on the characteristics of palm oilbiodiesel-diesel fuel blend." Egyptian Journal of Petroleum 27, no. 2 (2018): 187-194. https://doi.org/10.1016/i.ejpe.2017.03.002

[17] Benjumea, Pedro, John Agudelo, and Andres Agudelo. "Basic properties of palm oil biodiesel-diesel blends." Fuel 87, no. 10-11 (2008): 2069-2075.

https://doi.org/10.1016/j.fuel.2007.11.004 